University of New Hampshire

University of New Hampshire Scholars' Repository

Applied Engineering and Sciences Scholarship

Applied Engineering and Sciences

$1-1-2018$

\title{
Representative Names of Computing Degree Programs Worldwide
}

\author{
Mihaela C. Sabin \\ University of New Hampshire, Manchester, mihaela.sabin@unh.edu \\ Paul Snow \\ Dr. Simon \\ University of Newcastle, Australia \\ John Impagliazzo \\ Hofstra University \\ Alison Clear \\ Eastern Institute of Technology, New Zealand
}

See next page for additional authors

Follow this and additional works at: https://scholars.unh.edu/unhmcis_facpub

\section{Comments}

(c) ACM, New York, NY, USA,2018. This is the author's version of the work. It is posted here for your personal use. Not for redistribution. The definitive Version of Record was published in ACE 2018: 20th Australasian Computing Education Conference, https://dl.acm.org/citation.cfm?id=3160501.

\section{Recommended Citation}

Sabin, Mihaela, Paul Snow, Simon, John Impagliazzo, Alison Clear, and Yan Timanovsky. 2018.

"Representative Names of Computing Degree Programs Worldwide." In ACE 2018: 20th Australasian Computing Education Conference. Brisbane, QLD, Australia: ACM, New York, NY, USA. https://doi.org/ 10.1145/3160489.3160501.

This Conference Proceeding is brought to you for free and open access by the Applied Engineering and Sciences at University of New Hampshire Scholars' Repository. It has been accepted for inclusion in Applied Engineering and Sciences Scholarship by an authorized administrator of University of New Hampshire Scholars' Repository. For more information, please contact Scholarly.Communication@unh.edu. 


\section{Authors}

Mihaela C. Sabin, Paul Snow, Dr. Simon, John Impagliazzo, Alison Clear, and Yan Timanovsky 


\section{Representative Names of Computing Degree Programs Worldwide}

\author{
Mihaela Sabin \\ University of New Hampshire \\ USA \\ mihaela.sabin@unh.edu

$$
\text { John Impagliazzo }
$$ \\ Hofstra University \\ USA \\ john.impagliazzo@hofstra.edu
}

\author{
Paul Snow \\ Independent Consultant \\ USA \\ paulusnix@gmail.com \\ Alison Clear \\ Eastern Institute of Technology \\ New Zealand \\ aclear@eit.ac.nz
}

\author{
Simon \\ University of Newcastle \\ Australia \\ simon@newcastle.edu.au \\ Yan Timanovsky \\ ACM \\ USA \\ timanovsky@hq.acm.org
}

\begin{abstract}
Through the auspices of ACM and with support from the IEEE Computer Society, a task group charged to prepare the IT2017 report conducted an online international survey of computing faculty members about their undergraduate degree programs in computing. The purpose of this survey was to clarify the breadth of and disparities in nomenclature used by diverse communities in the computing field, where a word or phrase can mean different things in different computing communities. This paper examines the English-language words and phrases used to name the computing programs of almost six hundred survey respondents, and the countries in which those names are used. Over eight hundred program names analysed in this paper reveal six program names that together account for more than half of all program names. The paper goes on to consider possible correspondence between reported program names and the five areas of computing identified by the ACM. Names such as computer science and information technology appear to dominate, but with different meanings, while the names of other computing disciplines show clear geographic preferences. Convergence towards a very small number of highly representative program names in computing education worldwide might be deceptive. The paper calls for further examination and international collaborations to align program names with program curriculum content.
\end{abstract}

\section{CCS CONCEPTS}

- General and reference $\rightarrow$ Surveys and overviews; • Social and professional topics $\rightarrow$ Computing education programs;

\section{KEYWORDS}

Computing program names; international computing education; computing terminology; computing nomenclature

\section{ACM Reference Format:}

Mihaela Sabin, Paul Snow, Simon, John Impagliazzo, Alison Clear, and Yan Timanovsky. 2018. Representative Names of Computing Degree Programs Worldwide. In ACE 2018: 20th Australasian Computing Education Conference, January 30-February 2, 2018, Brisbane, Qld, Australia. ACM, New York, NY, USA, 8 pages. https://doi.org/10.1145/3160489.3160501

\section{INTRODUCTION}

The curriculum guidelines for undergraduate degree programs in information technology (IT) were updated and scheduled for release in $2017^{1}$. In 2015 the ACM conducted a survey of faculty members in computing departments worldwide to provide the IT2017 task group with international data to help with the development of globally relevant information technology (IT) curriculum guidelines. Two authors of this paper are members of the IT2017 task group, and so have access to the survey responses.

There are specific regularities in the ways computing professional societies name the profession of their membership [3]. Awareness of this, and of the variation in computing education terminology worldwide, could help with the formulation of international curricular recommendations and with professional communications in the English language for international adoption and implementation.

This paper examines the countries of survey respondents and the English-language names (including translations into English) of the degree programs listed by the respondents. The responses have been studied to better understand (1) geographic representation of the reported program names; (2) vocabulary composition of the names; and (3) possible correspondence between the names and the ACM designations of computing disciplines. The remainder of the paper describes the faculty survey, presents the key results in naming undergraduate computing programs, discusses implications for computing curricula worldwide, and concludes with recommendations for further studies. 


\section{SO, WHAT'S THE PROBLEM?}

Computing educational activities in multinational environments are becoming very common. Events such as conferences and symposiums are typically international in nature. However, some participants are becoming increasingly aware of difficulties in communicating with colleagues from different geographic regions or even from the same geographic region.

It is possible to cite many instances of jargon that are found in computing educational communities. The following are a few examples of the jargon and cacophony in nomenclature that currently exist in the literature and in professional discussions.

- The phrase ' $\mathrm{K}-12$ ' or ' $\mathrm{K} 12$ ' is meaningless in many parts of the world.

- Use of the words 'credit' or 'credits' is not universal.

- 'Advanced placement' (AP) is a US-centric phrase.

- The concepts of four-year universities and community colleges have little meaning outside northern America.

- The name 'information technology' has many different meanings worldwide.

- The phrase 'computing education' is much broader than 'computer science education', although even within the same region many people show no awareness of the distinction between these phrases.

As a first step in the process of dispelling some of the confusion and misconceptions, the IT2017 task group conducted a survey to ascertain some of the elements that contribute to misunderstandings, to gather data on the subject, and to help explain how educators and professionals might use such terminology.

\section{FACULTY SURVEY}

To help inform the IT2017 project, the ACM surveyed academic computing departments around the world in the early part of 2015. The survey, written in English, was distributed through several email broadcasts. User instructions described the purpose and sponsors of the survey and characterised the desired respondent as follows:

We reach out to you because your academic department offers an undergraduate (four-year) computing degree program and we value your opinion in this effort.

Two email broadcasts to contacts acquired from the International Book Information Service (IBIS) and one email broadcast to members of the ACM Special Interest Group for Information Technology Education (SIGITE) produced 540 responses. The first IBIS broadcast, in April 2015, went to 3000 US faculty members and 7000 international faculty members from countries in Africa, Asia, Australasia, Europe, and the Americas. A second broadcast the following month targeted a different sampling of unique contacts from the same IBIS list, this time reaching 1500 US faculty members and 3500 international faculty members.

Additionally, the survey was posted to IT faculty from a contact list compiled by a research study on the IT faculty profile [4] (approximately 900 contacts of IT faculty in the US, some of whom are SIGITE members). This survey outreach resulted in a further 42 responses. Finally, due to an apparent lack of response to the IBIS

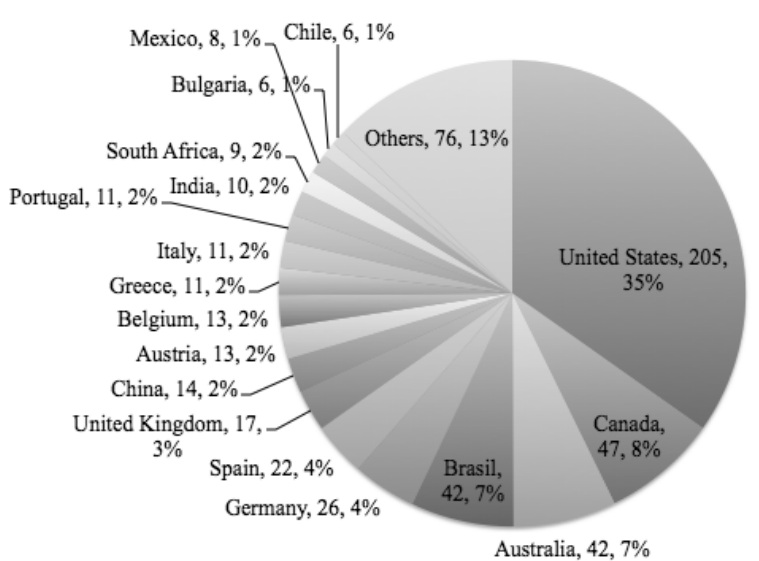

Figure 1: Countries of respondents

mailings from programs based in China, a Chinese translation of the survey was distributed to participants of two IT2017 workshops in China. With 15 responses from this approach, the survey received a total of 597 responses, a response rate of about 3.8\%.

The survey responses were given routine data cleaning by a statistician to eliminate spurious responses, to correct typographical errors and expand common abbreviations in free-text responses, and to recode 'other' responses into admissible answers when possible.

The survey asked 16 questions with a mix of multiple-choice and free-form responses. This paper is based on the responses to two of the questions, addressing the respondent's country and the names of degrees offered by the respondent's department.

The second of these questions solicited free-text responses: "The names of the computing degree programs in my department are...". Two response fields were offered, one for graduate programs and one for undergraduate programs, the latter being characterised in the survey as 'four-year programs'. It is not clear whether this characterisation affected the response rate from some countries, as three-year undergraduate degree programs are the norm in many countries and regions such as the UK, Europe, and Australasia. This paper considers only the responses to the undergraduate program part of this question, so we will use the term program to refer to an undergraduate computing degree program, and program name (or just name) to refer to the program's discipline or field of study, as reported by the respondent (for example, "information systems").

\section{RESULTS}

A total of 589 computing faculty from 50 countries indicated the country of their institution, 35\% in the United States and 65\% in other countries (Figure 1). The top ten countries accounted for $75 \%$ of all participants.

Of 591 responses to the question about program names, 528 (89\%) were in English, either in English alone or as the respondent's translation into English from another language. Some of those responses gave only generic program names, such as Bachelor of Science or Bachelor of Arts. Of the 528 responses in English or English translation, 470 from 44 countries reported one or more 
Table 1: Responses naming computing programs in English

\begin{tabular}{lcc}
\hline Geographic group & $\begin{array}{c}\text { Responses } \\
(\mathrm{N}=470)\end{array}$ & $\begin{array}{c}\text { Names } \\
(\mathrm{N}=833)\end{array}$ \\
\hline USA & $183(39 \%)$ & $349(42 \%)$ \\
Other countries & $285(61 \%)$ & $480(58 \%)$ \\
English-speaking & $111(24 \%)$ & $230(28 \%)$ \\
Other languages & $174(37 \%)$ & $250(30 \%)$ \\
Unintelligible country name & $2(<1 \%)$ & $4(<1 \%)$ \\
\hline
\end{tabular}

computing-specific program names, together encompassing a total of 833 program names. If a respondent mentioned more than one program with the same program name (e.g. "Bachelor in Informatics, and Bachelor with Honors in Informatics"), that was counted as a single instance of that program name. These 470 responses and 833 program names are the basis for all analysis of program names in this paper.

\subsection{Geography of program names}

Question 1 of the survey asked for the country of the respondent's institution: "The country in which the main campus of my institution of higher learning exists is...". Of the 470 responses that provided computing-specific program names in English or English translation, 183 (39\%) were from the United States, 285 (61\%) were from other countries, and two were unintelligible (Table 1).

Among the 285 responses from outside the United States, 111 were from countries where English is an official language. Three countries accounted for $77 \%$ of these responses: Australia (40 respondents), Canada (32), and the United Kingdom (14). The other countries in this category were India, Ireland, Kenya, New Zealand, Pakistan, the Philippines, Singapore, and South Africa, each of which had five or fewer responses. The 111 non-US English-area respondents together contributed 230 program names (28\%), and the 174 non-English respondents contributed 250 names (Table 1). Among the 174 non-English responses, two thirds were from Europe (115), a quarter from Latin America (43), and a tenth from Asia (16). Eight countries accounted for $68 \%$ of these responses, four of which had more than five responses: Brazil (36 names), Spain (20), Germany (18), and Austria (11).

\subsection{Vocabulary used in program names}

The 833 program names were analysed with a word-counting program. Connective words like "and" and "in" were ignored. Singular and plural forms of the same noun were treated as instances of a single word (technology and technologies, for example). Except for the combining of singular and plural, distinct words built on the same stem (computer, computing, computation, computational, etc) were tallied as different words.

Responses both from the United States and from other countries showed a strong preference for a relatively small set of words. Within each group, the eleven most frequent words accounted for more than $80 \%$ of the words used in program names. (Eleven was chosen rather than ten for ease of comparison with a parallel
Table 2: Fourteen words comprising the eleven most used words in 833 program names in three regions; each entry shows the word's rank and proportion of total words in its region; equal ranks are marked with asterisks

\begin{tabular}{lccc}
\hline $\begin{array}{l}\text { Word in } \\
\text { program name }\end{array}$ & $\begin{array}{c}\text { World rank } \\
\& \%(\mathrm{~N}=1894)\end{array}$ & $\begin{array}{c}\text { US rank } \\
\& \%(\mathrm{~N}=822)\end{array}$ & $\begin{array}{c}\text { Non-US rank } \\
\& \%(\mathrm{~N}=1064)\end{array}$ \\
\hline computer & $1(18 \%)$ & $2(17 \%)$ & $1(18 \%)$ \\
information & $2(16 \%)$ & $1(22 \%)$ & $4(11 \%)$ \\
science & $3(14 \%)$ & $3(14 \%)$ & $2(13 \%)$ \\
technology & $4(11 \%)$ & $4(14 \%)$ & $5(9 \%)$ \\
engineering & $5(8 \%)$ & $7(2 \%)$ & $3(12 \%)$ \\
system & $6(6 \%)$ & $5(8 \%)$ & $6(6 \%)$ \\
software & $7(3 \%)$ & $10(2 \%)$ & $7(4 \%)$ \\
informatics & $8(2 \%)$ & $13^{*}(1 \%)$ & $8(4 \%)$ \\
computing & $9(2 \%)$ & $18^{*}(<1 \%)$ & $9(3 \%)$ \\
management & $10(2 \%)$ & $6(3 \%)$ & $12^{*}(1 \%)$ \\
business & $11(1 \%)$ & $18^{*}(<1 \%)$ & $10(2 \%)$ \\
development & $12^{*}(1 \%)$ & $11(1 \%)$ & $11(1 \%)$ \\
security & $12^{*}(1 \%)$ & $8^{*}(2 \%)$ & $14(1 \%)$ \\
network & $14(1 \%)$ & $8^{*}(2 \%)$ & $25^{*}(<1 \%)$ \\
\hline
\end{tabular}

analysis discussed in section 4.5.) Moreover, there was considerable overlap between the two groups in the words they favoured. Fourteen words suffice to cover the two top eleven lists.

Table 2 shows these words and how they fared overall in the survey. We note again that we were unable to attribute countries to two of the responses (Table 1), which encompassed four program names. Eight of the words (the first seven overall and 'development') are among the eleven most used words both within and outside the United States. The remaining six words show some geographic differences in usage. Management, security, and network are markedly more popular in the United States, while informatics, computing, and business are relatively more popular in other countries. Together, these fourteen words account for about $87 \%$ of all 1894 words used in the 833 program names.

\subsection{Principal names}

The 833 program names define a name space of 234 distinct program names. To determine distinctness, we considered plural and singular forms the same (for example, communication technology was considered to be the same as communications technologies). However, as in the previous subsection, except for pluralisation, distinct words built from a common stem were treated as different words. Punctuation was ignored, ampersands $(\&)$ were replaced with and, and common abbreviations such as IT, MIS, and CS were expanded.

Only seven of the 234 distinct program names were used ten or more times. Of these seven, one (computer information systems) contained a name that was itself used more than ten times (information systems).

Let us introduce two more definitions. We call a principal name a program name that was used ten or more times and that does not contain a shorter name that was itself used ten or more times. The six principal names so identified - computer science, information 


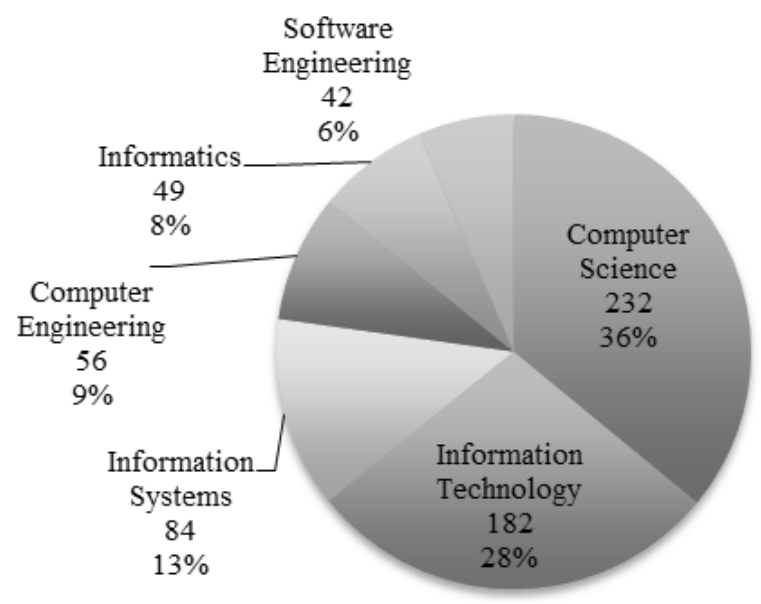

Figure 2: Principal name use in principal name phrases

technology, information systems, computer engineering, software engineering, and informatics - together accounted for more than half of all program names (454 out of $833,55 \%$ ).

We call a principal name phrase a program name that is itself a principal name or that includes at least one principal name (as, for example, 'computer science for business' includes 'computer science'). Three quarters of all program names (629 out of 833, $75.5 \%$ ) were principal name phrases. Among the 629 principal name phrases, there were 645 principal name occurrences. (Some phrases have two principal names, such as 'computer science and software engineering' or 'information technology and informatics').

Figure 2 shows how many times each principal name was used in a principal name phrase. Fully $64 \%$ of program names include the principal names computer science $(36 \%)$ and/or information technology $(28 \%)$.

\subsection{Geography of principal names}

The most prevalent principal name overall, computer science, showed some geographical balance: 102 of its 232 uses (44\%) were from the United States, compared with $42 \%$ of the 833 program names being from there. Computer science is both frequently and widely used in program names throughout the world.

Considering principal name phrases, computer engineering, informatics, and software engineering, by themselves or as part of longer names, were proportionally more prevalent outside the United States (126 of their 147 uses, 86\%), while information systems and information technology were used more in the United States (153 of their 266 uses, $60 \%$ )

Turning to standalone principal names, geographic differences were observed in the usage of all principal names apart from computer science. Figure 3 counts the standalone uses of each of the six principal names, broken out by respondents' locations: the United States; another English-speaking country; or a country where English is not an official language.

Fully $90 \%$ of the standalone uses of computer engineering (36 of 40 uses) were from outside the United States, mostly from countries

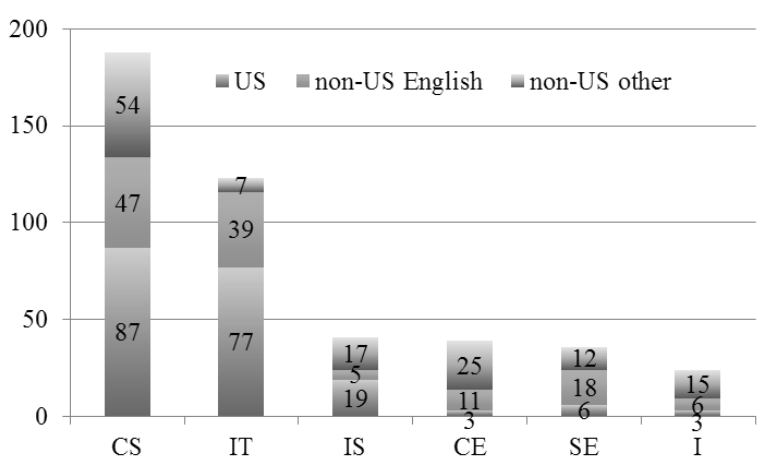

Figure 3: Principal names by location

where English is not an official language (25 uses, $62 \%$ ). The usage pattern for informatics was similar ( 21 of 24 uses from outside the United States, 15 of those from countries where English is not an official language). Software engineering was also found mostly outside the United States (30 of 36 uses, $83 \%$ ), but with stronger use from English-speaking countries (18 of 36 uses, 50\%).

Among principal names, only information technology was strongly favoured in the United States (77 of 123 uses, 63\%) compared with the overall US share of program names (about $42 \%$ of the 833 found in the survey). Only seven of its uses (6\%) were from non-English-speaking countries. As Figure 3 shows, information technology was the least used principal name in countries where English is not an official language. Within the survey sample, then, the use of information technology as a stand-alone program name was almost entirely confined to the English-speaking world.

\subsection{Vocabulary apart from principal names}

The dominance of a handful of principal names partly explains the observed preference for a small number of individual words for composing program names. The top eight words used worldwide for program names in the survey (Table 2) are the eight distinct words that appear within the six principal names. A question that arises is whether the principal names are the only coordinating factor in choosing program name vocabulary.

To investigate this question, we removed the principal names from the 833 program names, but kept the rest of each name for analysis. Thus 'informatics and music' would be edited to just 'music', while 'informatics' and 'informatics and computer science' would be completely removed, since nothing substantive would be left after editing. As before, connecting words were ignored, and plural nouns were combined with singular forms, but otherwise distinct words built on the same stem were treated as different words.

The redacted list was put through the same single-word analysis as described in section 4.2. Once again, the responses both from the United States and from other countries still showed a strong preference for a small set of words. While the effect is less pronounced with the removal of the principal names, it remains interesting.

Table 3 shows the top eleven words from inside and outside the United States, and overall. There are two-way ties for tenth place 
Table 3: Fifteen words comprising the eleven most used words in three regions after removing principal names; each entry shows the word's rank and proportion of total words in its region; equal ranks are marked with asterisks

\begin{tabular}{lccc}
\hline $\begin{array}{l}\text { Word in } \\
\text { program name }\end{array}$ & $\begin{array}{c}\text { World rank } \\
\& \%(\mathrm{~N}=668)\end{array}$ & $\begin{array}{c}\text { US rank } \\
\& \%(\mathrm{~N}=274)\end{array}$ & $\begin{array}{c}\text { Non-US rank } \\
\& \%(\mathrm{~N}=392)\end{array}$ \\
\hline computer & $1(8 \%)$ & $1(14 \%)$ & $6(5 \%)$ \\
engineering & $2(8 \%)$ & $12^{*}(2 \%)$ & $1(12 \%)$ \\
computing & $3(6 \%)$ & $17^{*}(2 \%)$ & $2(9 \%)$ \\
information & $4(5 \%)$ & $2(9 \%)$ & $10^{*}(3 \%)$ \\
management & $5(5 \%)$ & $3(8 \%)$ & $8^{*}(3 \%)$ \\
technology & $6(5 \%)$ & $7(4 \%)$ & $5(5 \%)$ \\
system & $7(5 \%)$ & $9(3 \%)$ & $4(6 \%)$ \\
business & $8^{*}(4 \%)$ & $17^{*}(2 \%)$ & $3(6 \%)$ \\
science & $8^{*}(4 \%)$ & $4(7 \%)$ & $17(2 \%)$ \\
development & $10^{*}(4 \%)$ & $8(4 \%)$ & $7(4 \%)$ \\
security & $10^{*}(4 \%)$ & $5^{*}(5 \%)$ & $10^{*}(3 \%)$ \\
network & $12(3 \%)$ & $5^{*}(5 \%)$ & $24^{*}(1 \%)$ \\
game & $13^{*}(2 \%)$ & $17^{*}(2 \%)$ & $8^{*}(3 \%)$ \\
mathematics & $17(2 \%)$ & $10^{*}(3 \%)$ & $20^{*}(1 \%)$ \\
administration & $23^{*}(1 \%)$ & $10^{*}(3 \%)$ & $\mathrm{n} / \mathrm{a}$ \\
\hline
\end{tabular}

on all three lists, which is why eleven items have been emphasised throughout. It takes fifteen words to cover the lists of eleven words from both regions, as compared with fourteen before the redaction of principal names.

Twelve of the fourteen words from Table 2 reappear here. Informatics was eliminated by the rules of the redaction, and software did not make the top eleven lists as it appeared mainly in the software engineering principal name, which was removed. The three new words that appear in Table 3 are mathematics, game, and administration. Seven words appear on both top-eleven lists: computer, information, management, technology, system, development, and security. The other eight words show marked geographic preference differences, four being more popular in the United States (science, administration, mathematics, and network) and four being more popular elsewhere (engineering, computing, business, and game). Among them, these fifteen words account for about $65 \%$ of all words used in the program names. While that is less than the $85 \%$ share for the fourteen spanning words before redaction, it is still a remarkable level of concentration on a few words for building academic program names.

\section{DISCUSSION}

Remarkably, 234 distinct program names in a space of 833 names reveal no more than six principal names. Five of these names match exactly the computing disciplines defined by the ACM: computer engineering, computer science, information systems, information technology, and software engineering [1].

\subsection{Six names, five computing disciplines}

Whether a program name used a standalone principal name or a principal name phrase, there were consistently similar shares of the six names among all program names within and outside the United

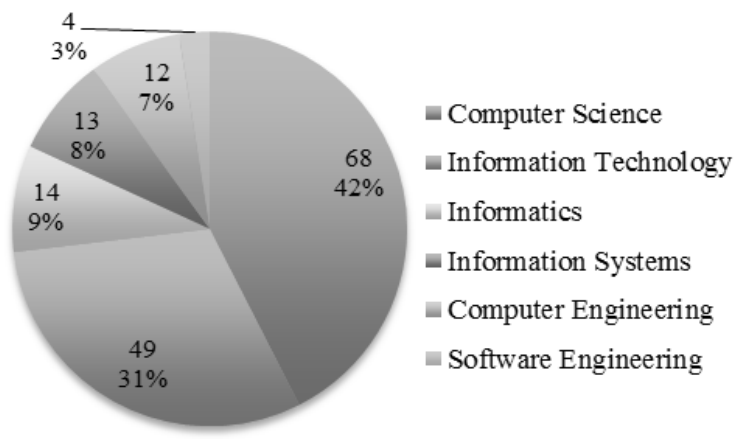

Figure 4: Principal names reported as program names by single-program departments

States, and consequently worldwide. Two notable results were that more than half of program names (56\% in US, $53 \%$ elsewhere) correspond to the six principal names; and that three quarters of program names (77\% in US, 74\% elsewhere) are principal name phrases.

5.1.1 Computing department preferences. Single-program departments appear to dominate the computing department space worldwide (284 out of $470,60 \%$ ), in the United States (95 out of $183,52 \%$ ), and elsewhere (188 out of $285,66 \%$ ). As the number of program names in a response increases, the number of respondents with that number of names decreases. What stands out is that in more than half of the single-program departments the program name coincides with one of the six principal names ( 160 out of 284 , $56 \%)$.

A closer look at departments that use principal names as standalone terms for their programs shows that computer science and information technology are the most prevalent names in both single-program and multi-program departments. Figure 4 shows that among single-program departments the most prevalent program name was computer science (68 uses, $42 \%$ of 160 ), followed closely by information technology ( 49 uses, $31 \%$ ). The usage of the remaining principal names, informatics (9\%), information systems (8\%), and computer engineering (7\%), had relatively similar shares of program names. The least prevalent program was software engineering.

A similar picture emerges from multi-program departments: computer science and information technology are the most prevalent, together accounting for about two-thirds of the program names. However, the order of the remaining four principal names was reversed: software engineering, computer engineering, and information systems were all about $10 \%$, while informatics was the least prevalent at $3 \%$. This might suggest that multiple programs are less common in Europe, where the name informatics is most common.

5.1.2 Geographic variations. The usage of principal names by single-program departments differs dramatically between the United States and elsewhere. Except for three respondents (5\%) reporting information systems programs, all US single-program departments named their program either information technology or computer 


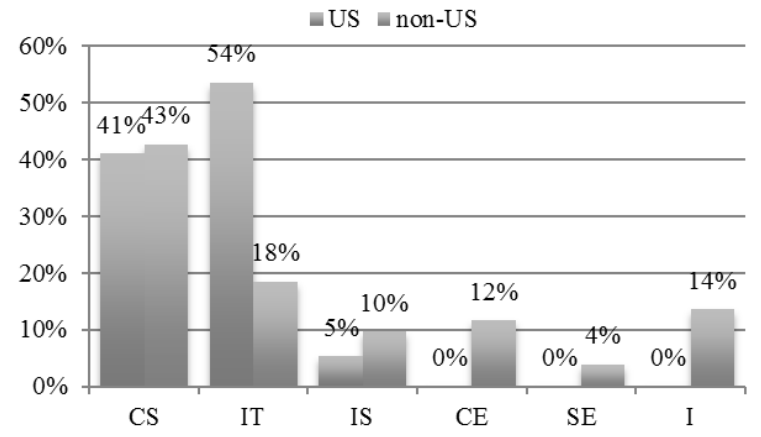

Figure 5: Principal names by location reported by singleprogram departments

science, with information technology being in the majority (30 versus 23 , or $54 \%$ versus $41 \%$ of 56 ). No US single-program department reported computer engineering or software engineering (Figure 5).

Outside the United States, computer science was the most frequent (44 of 103, 43\%), followed by information technology as a distant second (19, or 18\%). In contrast, the remaining four programs were represented with at least $10 \%$ share each. Engineering $(16 \%)$ and informatics (14\%) had relatively similar representation and accounted for $30 \%$ of all programs.

Considering single-program departments, we recall from Section 4.4 that the use of information technology as a standalone name was almost entirely an English-language phenomenon. Among multi-program departments, 74 respondents included information technology in their list of programs, frequently in combination with computer science both in the United States (83\% of 74 respondents) and elsewhere $(74 \%)$. Notably, only five of these 74 respondents came from a country where English is not an official language.

\subsection{More geographic contrasts}

While computer science shows geographic balance in its program name usage, computer engineering, for example, is more prevalent in countries where English is not an official language. A brief historical account of professional societies and accreditation of engineering and computing offers some interesting insights.

Professional engineering societies were established more than half a century before the emergence of computing societies such as ACM in 1947, British Computer Society (BCS) in 1957, New Zealand Computer Society (now IITP) in 1960, Australian Computer Society (ACS) in 1966, and Gesellschaft für Informatik in Germany in 1969. The development of academic programs and their accreditation standards followed a similar pattern of a considerable time gap between engineering and computing.

Relatively few computing programs are professionally accredited in the United States, while accreditation is expected in other English-speaking countries (Australia, Canada, UK), and required of all university programs in Germany. While graduates of computer engineering receive professional status like any other engineers, by applying for a license or through government regulation of their academic programs, graduates of the other computing programs experience professional status achievement differently with their country of origin [6]. In the UK, BCS can confer professional designations, including Chartered Scientist and Chartered IT Professional, because BCS joined the Engineering Council in the UK in 1985. In Latin America, computing programs fall under the umbrella of systems engineering and graduates are regarded as engineers. Indeed, it has been suggested that in Latin America only an engineering degree is worth having, which leads to the offering of degrees in such areas as tourism engineering.

Another word that shows a pronounced geographical contrast is informatics. The only single-word principal name, informatics, like computer engineering, is predominantly used in non-Englishspeaking countries [5]. Known under different names in different European countries and languages (Informatik, informatique, or informatica), informatics in higher education is used interchangeably with computer science or translated as computer science (in Germany, Netherlands, and Switzerland) [5]. Informatics Europe ${ }^{2}$, representing the European academic and research community in information and computer sciences, names its annual summit " $\mathrm{Eu}$ ropean Computer Science Summit". European secondary education considers informatics and computer science to be synonymous $[2,8]$. It might therefore make sense to merge the European usage of computer science and informatics under one principal name. However, it is by no means clear whether that name should be informatics or computer science, or whether the names correspond to the same sorts of program as they do in other regions. Furthermore, it seems unlikely that the many European countries that use the name informatics would consent to devising more literal translations of computer science, and equally unlikely that the ACM and the many English-speaking users of computer science would agree to replace that phrase with informatics.

\subsection{How program names are chosen}

A little introspection suggests that program names can be chosen in one of three ways. In some cases they may be determined by regulation, perhaps at a professional level or perhaps at a government level as in Estonia [7] or Germany [6]. If the choice is left to the institution or the department, the name might be chosen as a point of association: there are other degrees with this name; they are respected, and people seem to know what the name signifies; therefore it makes sense to use the same name. Alternatively, the name might be chosen as a point of distinction: there are many degrees with this name, and we wish to establish our degree as different from them, so we will choose a name that is not so common.

The high prevalence of a small number of principal names suggests that naming as a point of association is more common than naming as a point of distinction. Program names are often chosen because there are other programs with the same name. What has not been established is whether those programs also have highly similar content: that is, whether the same names mean the same thing. This concern is further justified by naming that shows an excessive or multiplied point of association. This is the case when a single degree program name incorporates two principal names, such as "Information Technology and Informatics" or "Computer

\footnotetext{
${ }^{2} \mathrm{http://www.informatics-europe.org/}$
} 
Science and Software Engineering”, or combines them in original ways, such as "Informatics Engineering", "Information Systems and Technology", or "Information Technology Software Development". These examples raise questions about the implications of program naming for the programs' curriculum guidelines, accreditation, and professional society affiliations.

\subsection{Limitations of the study}

The ACM has defined five areas of computing, including computer science and information technology. However, a recent international study [7] concluded that these names and others are used to mean different things in different places, and sometimes even in the same place. While a program called information technology might signify a particular set of courses to the ACM, and in countries that base their terminology on ACM guidelines, there is evidence of other information technology programs that are more like an ACM-style computer science program.

Some recipients of this survey were selected as members of an information technology education association, and some others as US information technology educators; this might bias the responses somewhat towards information technology and the US understanding of that phrase. Furthermore, because the survey was anonymous, we have no way of knowing whether there were multiple respondents from some departments.

As noted at the end of section 3, it is possible that some potential respondents were dissuaded from contributing by the indication that the survey was interested in four-year degrees, when in many countries the normal undergraduate degree extends over only three years.

For these reasons it must remain clear that this study is an analysis of program names as reported by respondents to this particular survey, and cannot be used as evidence of the distribution of program names more broadly. It can certainly not be used as evidence of program contents, as this question was not canvassed in the survey, and indeed would be difficult to capture in such an instrument.

\section{CONCLUSION AND FURTHER WORK}

A task group nominated by the ACM Education Board was charged to update the curriculum guidelines for undergraduate degree programs in information technology by 2017. Work on the IT2017 report benefited from an online international survey circulated by ACM to almost 16,000 computing faculty in early 2015 . Two thirds of the survey recipients, and about the same proportion of respondents, were from outside the United States. Analysis of 470 responses that generated 833 program names from 44 countries led to the following significant findings: six distinct names account for more than half of all name uses, and match the ACM names of the five computing disciplines; and the names computer science and information technology comfortably dominate the entire name space $(69 \%)$.

It is tempting to conclude from this analysis that computing degree programs fall principally into two groups, computer science (CS) and information technology (IT), and that there is worldwide acceptance that the ACM's five computing disciplines configure the computing education landscape. However, this temptation must be resisted. All that can be concluded is that the English-language names of the computing programs reported by the respondents of this survey fall principally into widely expected groups whose identity is informed by accreditation requirements and curricular guidelines and professional designations from $\mathrm{ACM}$ and other professional societies. The distinction between the programs themselves and their names is a different and extremely important matter that requires further study. In particular, a case has been made [7] that the name information technology in Australasia is a better match with computer science in northern America than with information technology in northern America. Furthermore, this survey has uncovered little use of the name information technology or its equivalent in languages other than English. Therefore extreme care must be taken in any attempt to match worldwide programs to ACM disciplines purely on the basis of their names.

The results of this survey clearly indicate the need for international collaboration in determining curriculum guidelines, $\mathrm{fu}$ ture areas of computing, and the subsequent naming of degree programs. Further study is called for into the contrasts between English-speaking and non-English-speaking countries regarding informatics and computing-related engineering programs. In addition, further study is called for into uses of the same name, such as information technology, for degree programs that are clearly different in content. The study shows that terms for computing disciplines have been established, but differential definitions have not. Research is required into the types of degree program that use the many names elucidated in this analysis, although the goal of a worldwide correspondence between program names and program content is almost certainly unattainable.

In summary, the dominant terms in program naming correspond reasonably well with the terminology used in ACM/IEEE documents. Unfortunately, the ACM/IEEE definitions of those terms for standards purposes may not correspond with their actual usage around the world. In principle it should be possible to remedy this mismatch, but to do so will require a great deal of cooperation and compromise. In the meantime, it is important for all computing educators to understand the variation in usage of degree names, so that they may better understand one another when discussing the degrees that they offer.

\section{ACKNOWLEDGMENTS}

The authors are grateful to the ACM for its support of the IT2017 task group, and for facilitating the administration and analysis of the survey.

\section{REFERENCES}

[1] Association for Computing Machinery (ACM) and Association for Information Systems and IEEE Computer Society, Joint Task Force for Computing Curricula 2005. Computing curricula 2005: the overview report. ACM, New York, USA. https://doi.org/10.1145/1124706.1121482

[2] Yvonne Buettner, Charles Duchâteau, Catherine Fulford, Pieter Hogenbirk, Mike Kendall, and Raymond Morel. 2000. Information and communication technology in secondary education: a curriculum for schools. UNESCO, Paris, France. http //wwwedu.ge.ch/cptic/prospective/projets/unesco/en/

[3] Alison Clear. 2015. What's in a name? A taxonomy of computing education terminology. ACM Inroads 6, 2 (2015), 7-9.

[4] Barry M Lunt and Bill Paterson. 2014. An academic profile of IT faculty in the USA In Proceedings of the 15th Annual Conference on Information Technology Education (SIGITE '14). ACM, New York, USA, 163-166. https://doi.org/10.1145/2656450. 2656455

[5] Cristina Pereira and Bertrand Meyer. 2013. Informatics education in Europe: institutions, degrees, students, positions, salaries - key data 2008-2012. Informatics 
Europe, Zürich, Switzerland

[6] Stephen Seidman. 2014. Computing: an emerging profession? ACM Inroads 5, 4 (2014), 6-11.

[7] Simon, Alison Clear, Janet Carter, Gerry Cross, Atanas Radenski, Liviana Tudor, and Eno Tõnisson. 2015. What's in a name?: international interpretations of computing education terminology. In 2015 ITiCSE Working Group Reports (ITICSEWGR '15). ACM, New York, USA, 173-186. https://doi.org/10.1145/2858796.2858803

[8] Mary Webb, Niki Davis, Tim Bell, Yaacov J Katz, Nicholas Reynolds, Dianne P Chambers, and Maciej M Sysło. 2017. Computer science in K-12 school curricula of the 21st century: why, what and when? Education and Information Technologies 22, 2 (Mar 2017), 445-468. https://doi.org/10.1007/s10639-016-9493-x 